\title{
Semantic contribution to verbal short-term memory: Are pleasant words easier to remember than neutral words in serial recall and serial recognition?
}

\author{
Catherine Monnier and Arielle Syssau \\ Université Paul Valéry, Montpellier, France
}

\begin{abstract}
In the four experiments reported here, we examined the role of word pleasantness on immediate serial recall and immediate serial recognition. In Experiment 1, we compared verbal serial recall of pleasant and neutral words, using a limited set of items. In Experiment 2, we replicated Experiment 1 with an open set of words (i.e., new items were used on every trial). In Experiments 3 and 4, we assessed immediate serial recognition of pleasant and neutral words, using item sets from Experiments 1 and 2. Pleasantness was found to have a facilitation effect on both immediate serial recall and immediate serial recognition. This study supplies some new supporting arguments in favor of a semantic contribution to verbal short-term memory performance. The pleasantness effect observed in immediate serial recognition showed that, contrary to a number of earlier findings, performance on this task can also turn out to be dependent on semantic factors. The results are discussed in relation to nonlinguistic and psycholinguistic models of short-term memory.
\end{abstract}

The purpose of the experiments conducted here was to identify a new semantic factor-namely, pleasantnessthat is assumed to have an impact on verbal short-term memory (STM) performance. We explored the influence of this semantic factor on two STM tasks: immediate serial recall and immediate serial recognition.

The role of long-term knowledge in serial recall no longer needs to be demonstrated. However, although the lexical factors that affect immediate serial recall performance have already been clearly identified and examined in a large number of studies (e.g., Hulme, Maughan, \& Brown, 1991; Hulme et al., 1997; Roodenrys, Hulme, Lethbridge, Hinton, \& Nimmo, 2002), the semantic factors likely to have an impact on immediate recall are still largely undiscovered. We know today that immediate serial recall is better for (1) high-imageability/concrete words versus low-imageability/abstract words (Allen \& Hulme, 2006; Bourassa \& Besner, 1994; Jefferies, Frankish, \& Lambon Ralph, 2006a; Walker \& Hulme, 1999), (2) abstract content words versus function words (Caza \& Belleville, 1999), and (3) semantically related versus unrelated words (Poirier \& Saint-Aubin, 1995; Saint-Aubin, Ouellette, \& Poirier, 2005; Saint-Aubin \& Poirier, 1999).

Two classes of STM models can provide an explanation for the effects of semantic factors on immediate serial recall: nonlinguistic models (e.g., Baddeley, Gathercole, \& Papagno, 1998; Nairne, 1990, 2002) and psycholinguistic models (e.g., Martin \& Gupta, 2004; Martin \& Saffran,
1997; Patterson, Graham, \& Hodges, 1994). Nonlinguistic models of STM posit the existence of a memory system specialized in short-term retention of verbal information. The redintegration theory originally proposed by Hulme et al. (1991) and Schweickert (1993) is one of the nonlinguistic models of STM. In this redintegration perspective, if temporary phonological representations are partially degraded at retrieval time, a redintegration process operates in order to reconstruct the incomplete traces on the basis of permanent phonological representations. In this view, to account for semantic effects in immediate serial recall, Poirier and Saint Aubin (1995) proposed that semantic activation contributes to the selection of phonologicallexical candidates for reconstruction. In contrast, psycholinguistic models of STM regard verbal STM as an integrated system that emerges from the language-processing system. These models propose that STM tasks involve multilevel representational capacities that serve comprehension and language production. Ongoing interaction between the semantic and the phonological representation levels helps keep phonological representations active and, thereby, prevents phonological decay throughout the STM task (Jefferies, Frankish, \& Lambon Ralph, 2006b; Patterson et al., 1994).

The first aim of the present study was to examine the impact of a new semantic factor on immediate serial recall, the emotional dimension of words, and more specifically, word pleasantness. According to Osgood and 
his colleagues (Osgood \& Suci, 1955; Osgood, Suci, \& Tannenbaum, 1957), word emotionality can be defined as a measure of the extent to which a word refers to a pleasant or an unpleasant meaning. Recently, Hadley and MacKay (2006, Experiment 1) showed that STM for certain unpleasant emotional words (i.e., taboo words) was better than that for neutral words. However, there are no studies of this type for pleasant words. Pleasant words are known today to be remembered better than neutral words in long-term memory tasks (e.g., Bock, 1986; Ferré, 2003). This pleasant-word advantage can be explained by the rich and diverse nature of long-term semantic representations. In the case of emotional words, Bower (1981) suggested that emotion nodes are added to semantic nodes in the network to represent the physiological and experiential components of the emotion denoted or connoted by the word (see also Niedenthal, Barsalou, Winkielman, Krauth-Gruber, \& Ric, 2005). In the same vein, some researchers have postulated that, unlike neutral-word representations, the long-term representations of emotional words contain autobiographical and self-reference units (Ochsner, 2000; Rogers, Kuiper, \& Kirkner, 1977). The fact that pleasant-word representations are semantically richer should show up as a pleasantness effect on immediate serial recall. The recall advantage of pleasant words is expected for both types of STM model (i.e., nonlinguistic and psycholinguistic).

Although the results published in the literature are consistent as far as the influence of semantics on immediate serial recall is concerned, the findings are scarcer and sometimes inconsistent when an immediate serial recognition task ${ }^{1}$ is used (Jefferies et al., 2006b; Knott, Patterson, \& Hodges, 2000; Walker \& Hulme, 1999). Jefferies et al. (2006b) found that imageability influenced immediate serial recognition performance. In contrast, Walker and Hulme observed no effects of concreteness on immediate serial recognition, and Knott et al. found equivalent serial recognition performance for relatively well-known and poorly comprehended words in a patient with semantic dementia.

The fact that semantic effects disappear in recognition tasks is in line with the predictions of certain proponents of the redintegration view, who have postulated that recognition tasks bypass the redintegration process (e.g., Gathercole, Pickering, Hall, \& Peaker, 2001; Walker \& Hulme, 1999). Indeed, insofar as items are presented again to participants at the time of test, information about item identity is directly available and, thus, eliminates the need for a reconstruction process. These authors have relied on the disappearance of lexical/semantic effects in recognition tasks to contend that the redintegration process is a late process that does not take effect until response time. However, the view that recognition tasks do not involve redintegration is not shared by all advocates of the redintegration model. Capaldi and Neath (1995) contended that all memory tasks require retrieving a mental representation that has to be compared with external information to meet the task demands. When the task is a serial recognition task, one can assume that during the second presentation of the list, the participant will generate an internal representation of the first list in order to compare it with the second and make a decision. In this sense, the serial recognition task not only brings item order to bear, but also may involve a redintegration process whenever the mental representation of the list has deteriorated. In this view, semantic factors are thus likely to affect the quality of the internal representation of the list items at testing time and, as a result, should have an impact on serial recognition performance (see Neath, 1997, for a similar argument based on a free reconstruction-of-order task).

The second objective of this study was to examine the impact of the pleasantness factor on serial recognition. In a redintegrative approach, if the recognition task indeed bypasses the redintegration process, the impact of the pleasantness factor on recognition performance should disappear. Otherwise, a pleasantness effect should show up. Finally, because psycholinguistic models of STM consider that semantic knowledge starts intervening at encoding time and continues throughout the task (including during retrieval), they predict that a pleasantness effect will still occur on recognition tasks.

\section{EXPERIMENT 1}

Experiment 1 was conducted to study how a new semantic variable, pleasantness, affects immediate serial recall. Because pleasant words are semantically richer and, thus, more readily accessible, both classes of STM models (i.e., nonlinguistic and psycholinguistic models) predict that pleasant words will be recalled better than neutral words.

\section{Method}

Participants. Thirty-two 1st-year psychology students at Paul Valéry University in Montpellier (mean age, 23 years) volunteered to participate in the experiment. They were all native speakers of French.

Materials. Two sets of 10 words were chosen: one of pleasant words and one of neutral words. The pleasant and neutral words were selected according to the Bonin et al. (2003) norms, where words are rated on emotional valence on a 5-point scale ranging from 1 (very negative) to 5 (very positive). The pleasant set consisted of words with a positive mean valence greater than 4.28 and a standard deviation lower than 0.79 (for the whole set, $M=4.50, S D=0.17$ ). To avoid awareness of the manipulation of word pleasantness, none of the pleasant words directly denoted a particular emotion (e.g., joy) but only connoted emotions (e.g., gift can evoke an emotion like joy). The neutral set consisted of words with a mean valence between 2.92 and 3.12 and a standard deviation below 1.14 (for the whole set, $M=2.99, S D=0.06$ ). There was a significant mean-valence difference between the two sets of words $\left[F(1,18)=676.8, M S_{\mathrm{e}}=\right.$ $0.02, p<.001]$.

The two selected word sets were matched on word length. In each set, nine words were two syllables long and one word was three syllables long. They were low-, medium-, and high-frequency words, matched across sets. Written word frequency in occurrences per million was determined from BRULEX (Content, Mousty, \& Radeau, 1990) as reported in the LEXIQUE database (New, Pallier, Ferrand, \& Matos, 2001; available at www.lexique.org/). An ANOVA showed that the two sets of words did not differ significantly in objective frequency [pleasant, $M=21.8, S D=26.8$; neutral, $M=21, S D=$ $\left.28.8 ; F(1,18)=0.004, M S_{\mathrm{e}}=774.98, p=.95\right]$. The two sets of words were also matched on concreteness [pleasant, $M=4.44$, $S D=0.50$; neutral, $M=4.70, S D=0.29 ; F(1,18)=1.94, M S_{\mathrm{e}}=$ $0.17, p=.18$ ], imageability [pleasant, $M=4.52, S D=0.26$; neu- 
tral, $\left.M=4.36, S D=0.51 ; F(1,18)=0.78, M S_{\mathrm{e}}=0.16, p=.39\right]$, and subjective frequency [pleasant, $M=3.26, S D=0.87$; neutral, $\left.M=3.30, S D=0.92 ; F(1,18)=0.01, M S_{\mathrm{e}}=0.80, p=.92\right]$, as determined from the Bonin et al. (2003) norms. Finally, care was taken to avoid phonological similarity by not including words that rhymed within or across sets.

Twenty pseudorandom lists of seven words were generated: 10 lists from the pleasant set and 10 lists from the neutral set. The lists were constructed so that no word appeared more than once in any given list and each word was presented in each serial position. All the participants saw all 20 lists, presented in a random order.

Two practice lists were generated, one with three words and one with four words. The practice words were neutral or pleasant and were not included in the experimental material.

Procedure. The participants were tested individually, in a single session lasting approximately $30 \mathrm{~min}$. First they performed a serial recall task, and then their speech rate on each of the 20 experimental words was measured.

For the serial recall task, each list was read to the participant at the rate of approximately one word per second. As soon as the last word had been read, the participants attempted to verbally recall the words in their order of presentation. They were instructed to say "pass" when they forgot a particular word in a list.

To assess speech rate, the participants were shown the experimental words one at a time and were asked to repeat each one 10 times as quickly and as clearly as they could. A stopwatch was used to time the 10 repetitions of each word. The total time taken for each word was then converted into words per second.

\section{Results}

For the serial recall task, credit was given only for words produced in the correct serial position. The score was the proportion of pleasant and neutral words correctly recalled. The mean serial recall scores are shown in Figure 1 . They were input into a two-way repeated measures ANOVA in which the factors were word pleasantness (pleasant vs. neutral) and serial position (Position 1 to Position 7 on the list). This analysis yielded a pleasant-word advantage $\left[F(1,31)=34.34, M S_{\mathrm{e}}=0.027, p<.001\right]$ and a serial position effect $\left[F(6,186)=70.35, M S_{\mathrm{e}}=0.043\right.$, $p<.001]$. A Scheffé analysis of the main effect of serial position showed that the primacy effect extended from Position 1 to Position 3 and that the recency effect was lim-

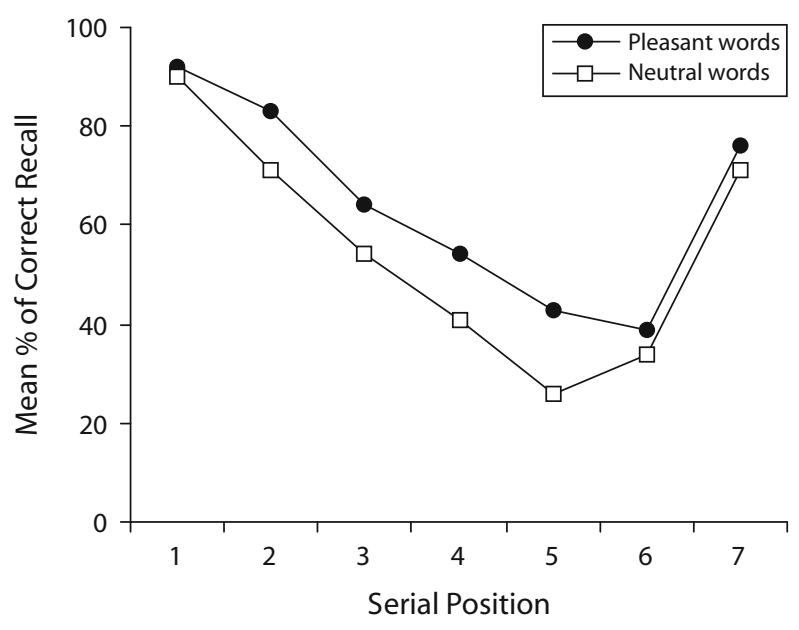

Figure 1. Mean percentages of correct recall for pleasant and neutral words as a function of serial position.
Table 1

Mean Proportions (With Standard Deviations) of Item and Order Errors for Pleasant and Neutral Words in Experiments 1 and 2 (Serial Recall)

\begin{tabular}{|c|c|c|c|c|c|c|c|c|}
\hline \multirow[b]{3}{*}{ Condition } & \multicolumn{4}{|c|}{$\begin{array}{c}\text { Experiment } 1 \\
\text { (Limited Word Set) }\end{array}$} & \multicolumn{4}{|c|}{$\begin{array}{c}\text { Experiment } 2 \\
\text { (Open Word Set) }\end{array}$} \\
\hline & \multicolumn{2}{|c|}{$\begin{array}{l}\text { Item } \\
\text { Errors }\end{array}$} & \multicolumn{2}{|c|}{$\begin{array}{c}\text { Order } \\
\text { Errors }\end{array}$} & \multicolumn{2}{|c|}{$\begin{array}{c}\text { Item } \\
\text { Errors } \\
\end{array}$} & \multicolumn{2}{|c|}{$\begin{array}{c}\text { Order } \\
\text { Errors } \\
\end{array}$} \\
\hline & $M$ & $S D$ & $M$ & $\overline{S D}$ & $M$ & $S D$ & $M$ & $S D$ \\
\hline Pleasant words & .21 & .10 & .18 & .09 & .21 & .08 & .11 & .10 \\
\hline Neutral words & .27 & .11 & .24 & .10 & .24 & .09 & .18 & .10 \\
\hline
\end{tabular}

ited to the last item. There was a significant interaction between word pleasantness and serial position $[F(6,186)=$ $\left.3.09, M S_{\mathrm{e}}=0.015, p<.01\right]$. A Newman-Keuls analysis of this interaction revealed that pleasant-word recall differed significantly from neutral-word recall in all the serial positions except for the first, sixth, and last.

The mean speech rate was 2.46 words per second for pleasant words $(S D=0.32)$ and 2.44 words per second for neutral words $(S D=0.31)$. This difference was not significant $[t(31)=1.44, p=.16]$.

Finally, an error analysis was conducted on the memory data. Two kinds of errors were tallied: item errors and order errors. An item error was defined as a missing or a wrong item (i.e., an item that did not belong to the list just presented). In each condition, the number of item errors was divided by the total number of words presented. An order error occurred when a just-presented word was recalled in the wrong serial position. In each condition, the number of order errors was divided by the total number of words correctly recalled, irrespective of serial position (Murdock, 1976). Table 1 shows the mean proportions and standard deviations of item and order errors in each condition. Item errors were much more frequent for neutral lists (.27) than for pleasant lists $(.21)[t(31)=5.12, p<.001]$. There were also more order errors for neutral lists (.24) than for pleasant lists $(.18)[t(31)=3.43, p<.01]$.

\section{Discussion}

The results of Experiment 1 indicated that pleasant words clearly facilitated immediate serial recall (as compared with neutral words) for the median serial positions. This facilitation was considerable, amounting to an average advantage of $9 \%$ across the serial positions. The pleasantness effect was observed at the item information level, leading to fewer item errors on pleasant words, but also at the order information level, leading again to fewer order errors on pleasant words. The pleasantness advantage seems to be independent of rehearsal process efficiency, because the speech rates for pleasant and neutral words were not significantly different. These results provide further support for a semantic contribution to immediate serial recall (e.g., Saint-Aubin et al., 2005; Walker \& Hulme, 1999). Note that the result pattern observed here is exactly like the one found by Allen and Hulme (2006) when they manipulated concreteness in immediate serial recall.

Because pleasantness had never been studied before in the STM framework, it seemed necessary to replicate 
these effects with new sets of words. In order to generalize the pleasantness effect, abstract words were included in the material of Experiment 2, and an open stimulus set was used (i.e., different words on every list).

\section{EXPERIMENT 2}

\section{Method}

Participants. The participants were 24 second-year psychology students at Paul Valéry University (mean age, 21 years), who received course credit for their participation. They were all native French speakers.

Materials. Fifty-six pleasant words and 56 neutral words were selected from the Bonin et al. (2003) and the Syssau and Font (2005) norms. In the Syssau and Font norms, words were rated on emotional valence, using a 3-point scale ( positive, negative, and neutral). The pleasant words selected according to the Bonin et al. norms consisted of words with a positive mean valence greater than 4.32 . The pleasant items selected from the Syssau and Font norms were words that were rated positively by at least $70 \%$ of the participants. The neutral set included words with a mean valence between 2.92 and 3.12 in the Bonin et al. norms and words that were rated neutrally by at least $70 \%$ of the participants in the Syssau and Font norms.

The pleasant and neutral sets of words were matched on number of phonemes. Each set included an equal number of words composed of $2,3,4,5,6,7,9$, and 10 phonemes. On average, pleasant and neutral words were composed of 4.5 phonemes. The two sets of selected words were also matched on word frequency, using the BRULEX database (Content et al., 1990) as reported in the LEXIQUE database (New et al., 2001). Each set consisted of 20 low-frequency words, 6 medium-frequency words, and 30 high-frequency words. Finally, concreteness was controlled. In each set, 22 abstract words and 34 concrete words were selected.

Sixteen lists of seven words ( 8 lists from the pleasant set and 8 lists from the neutral set) were randomly generated, each experimental word occurring only once. The participants were presented with all 16 lists, in a random order.

Two practice lists were generated, one with three words, the other with four words. The practice words were pleasant or neutral and were not included in the experimental material.

Procedure. The procedure for Experiment 2 was the same as that for Experiment 1 in most respects. The only difference concerned the way speech rate was assessed, which took into account word coarticulation duration. Ten pleasant and 10 neutral words were selected from the experimental sets. These words were matched on number of phonemes, frequency, and concreteness and were organized in pairs (five pleasant pairs and five neutral pairs) presented in a random order. The participants were instructed to repeat each pair as quickly as possible until they were told to stop (after about 10 repetitions). The time taken to do this was recorded and then converted into items articulated per second.

\section{Results}

For the serial recall task, each trial was scored for the number of words correctly recalled in serial position. These data, collapsed across participants and lists, are presented in Figure 2. They were input into a two-way repeated measures ANOVA in which the variables were word pleasantness (pleasant vs. neutral) and serial position (Position 1 to Position 7 on the list). There was a significant main effect of word pleasantness in favor of pleasant words $\left[F(1,23)=19.96, M S_{\mathrm{e}}=0.029, p<.001\right]$ and a significant main effect of serial position $[F(6,138)=$ $\left.44.11, M S_{\mathrm{e}}=0.040, p<.0001\right]$. A Scheffé analysis of the latter effect showed that the primacy effect was limited to

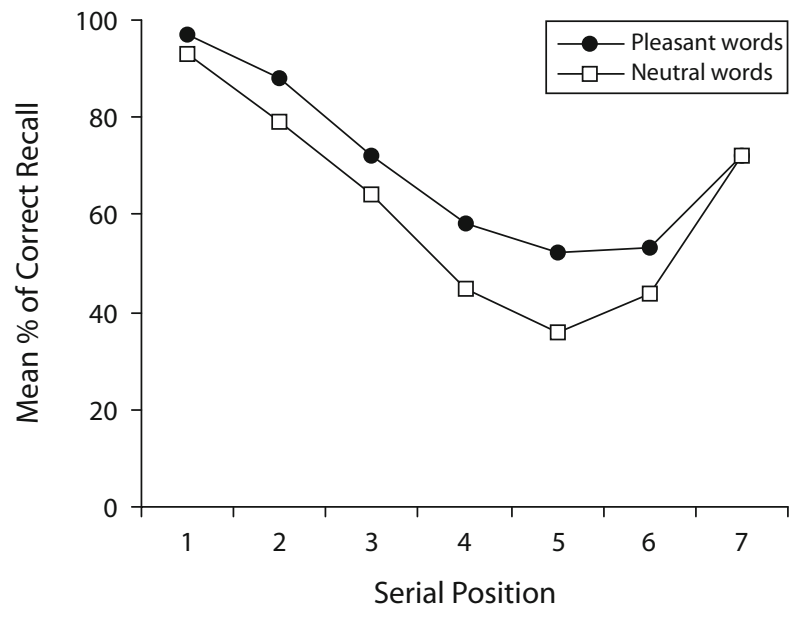

Figure 2. Mean percentages of correct recall for pleasant and neutral words as a function of serial position.

Positions 1 and 2 and that the recency effect concerned only the last item of the memory list. The interaction between these two variables was not significant $[F(6,138)=$ $\left.1.56, M S_{\mathrm{e}}=0.022, p=.16\right]$.

The mean speech rate for pleasant words was 2.44 words per second $(S D=0.33)$, whereas it was 2.42 words per second $(S D=0.30)$ for neutral words. This difference was not significant $[t(23)=0.91, p=.37]$.

As in Experiment 1, each recall error was classified into one of two mutually exclusive categories: item errors and order errors. Table 1 shows the mean proportions and standard deviations of item and order errors in each condition (pleasant vs. neutral words). Item errors were more frequent for neutral lists (.24) than for pleasant lists (.21) $[t(23)=2.30, p<.05]$. There were also more order errors on neutral lists (.18) than on pleasant lists (.11) $[t(23)=$ $3.87, p<.001]$.

\section{Discussion}

The main effects reported here are strikingly similar to the effects reported in Experiment 1, using a different set of words. Consequently, there is no doubt that pleasant words are remembered better than neutral words in an immediate serial recall task (average advantage of $8 \%$ across the serial positions). The only difference between Experiment 1 and this replication concerned the interaction between pleasantness and serial position, which was significant in Experiment 1, but not in Experiment 2. Nevertheless, at the descriptive level, there was still a trend toward a higher recall rate for pleasant words in the median serial positions. The small but nonsignificant trend observed in Experiment 2 could be due to the lower number of participants in this experiment, as compared with Experiment 1.

The pleasantness effect on immediate serial recall can be interpreted within the framework of the two classes of models presented above. According to the literature on emotions, pleasant words are semantically richer than neutral words. Long-term representations of pleasant words 
contain semantic, physiological (Bower, 1981; Niedenthal et al., 2005), and autobiographical (Ochsner, 2000; Rogers et al., 1977) information. Therefore, according to psycholinguistic models of STM, activation of the semantic level will be greater for pleasant words than for neutral words, and this will increase activation at the phonological level. In the redintegration view, the fact that pleasant words benefit from richer semantic information facilitates the selection of the best phonological candidate for recall whenever the phonological trace has faded at recall time.

Our error analyses showed that pleasantness affected the recall of both item and order information in the serial recall task (Experiments 1 and 2). The finding that pleasant words led to fewer item errors than did neutral words is in line with the results of previous studies in which semantic variables were manipulated (e.g., Saint-Aubin \& Poirier, 1999; Walker \& Hulme, 1999). On the other hand, an effect of lexical/semantic factors on order memory has generally not been observed in previous research (e.g., Hulme et al., 1997; Poirier \& Saint-Aubin, 1995; Walker \& Hulme, 1999). ${ }^{2}$ The finding that order information is retained better for pleasant than for neutral words seems inconsistent with the redintegration account. In this view, the redintegration process is assumed to operate at the item level to restore the degraded temporary trace of each item by comparing it with stable linguistic knowledge. The redintegration process is not assumed to restore the order in which the items were presented (Gathercole et al., 2001; Poirier \& Saint-Aubin, 1995, 1996; Saint-Aubin \& Poirier, 2000). In their current state, linguistic models of STM do not seem capable of accounting for this result either. A possible explanation of the pleasantness effect on order retention can be found in the source memory literature (Johnson, Hashtroudi, \& Lindsay, 1993). Source memory pertains to the context in which information was presented. It can be based on temporal (when) or spatial (where) aspects of events, on the modality in which events were presented, and on the perceptual details accompanying them. Doerksen and Shimamura (2001) observed a beneficial effect of emotion on source memory. They found better recognition of the color associated with emotional words, as compared with neutral words. In the present study, the location of an item in the list was marked temporally, so this made it an element of the presentation context. In this light, it is clear that the presentation order of pleasant words is easier to memorize than that of neutral words.

We saw that the results of Experiments 1 and 2 indicated a clear-cut pleasantness effect on immediate serial recall. The goal of the next two experiments was to see whether pleasantness would also affect performance on an immediate serial recognition task. In Experiment 3, we used the same limited set of words as that in Experiment 1, and in Experiment 4, the same open set of words as that in Experiment 2 was used.

\section{EXPERIMENT 3}

As was stated in the introduction, if, as certain advocates of the redintegration model contend, serial recognition tasks do not involve a redintegration process (Gathercole et al., 2001; Walker \& Hulme, 1999), the pleasantness effect observed in immediate serial recall should disappear. If, on the other hand, serial recognition tasks do call upon a redintegration process, as some other theorists assume (Neath, 1997), the pleasantness effect should still occur. Finally, predictions based on psycholinguistic models of STM also state that a pleasantness effect will occur in recognition tasks.

\section{Method}

Participants. Twenty-four 1st-year psychology students at Paul Valéry University (mean age, 20 years) participated in the experiment for course credit. All the participants were native French speakers.

Materials and Design. The materials were identical to those employed in Experiment 1 in terms of the experimental words (10 pleasant and 10 neutral words) and memory lists (ten 7-word lists from the pleasant set and ten 7-word lists from the neutral set). The 10 lists for each word type were used to construct 5 identical and 5 different lists for the serial recognition task. For the identical lists, the same sequence of items was presented twice. For the different lists, the second presentation contained the same items as the initial presentation, but the order of two adjacent items in the original list was switched on the second presentation. In order to optimize task difficulty, neither the first nor the last item in a list was affected by the transposition. The memory lists were divided into two sets (identified as Set A and Set B), each consisting of 5 pleasant lists and 5 neutral lists. In one version of the task, the Set A lists were the identical lists, whereas the Set B lists were the different lists. In the other version, transpositions were done on the Set A lists, whereas the Set B lists remained unchanged. Each participant was given one of these two versions. All the participants saw the 20 identical and different lists, which were presented in an unpredictable order, with the constraint of, at most, 4 lists of the same type in a row (i.e., identical or different).

In addition, three practice lists were generated, each containing seven neutral or pleasant words. These words were not included in the experimental material.

Procedure. The participants were tested individually or in groups of 2 or 3 . The experimenter read the lists at a rate of approximately one word per second. The last word on the first list presented and the first word on the second list presented were separated by a 2-sec interval. After hearing the second list, the participants were required to indicate whether the lists were identical or different by circling the answer "identical" or "different" on a response sheet.

\section{Results and Discussion}

Accuracy, assessed by $d^{\prime}$, was calculated for each condition (i.e., pleasant vs. neutral words) using the different responses to identical lists as false alarms. Accordingly, different lists are taken as the signal, and identical lists, as noise. The mean $d^{\prime}$ for pleasant words was $2.31(S D=$ $1.54)$, whereas it was $1.36(S D=0.92)$ for neutral words. This difference was significant $[t(23)=2.87, p<.01]$. So recognition accuracy was greater for pleasant than for neutral lists. Table 2 shows the hit and false alarm rates for each condition. Hit rates were higher for pleasant words (.75) than for neutral words $(.66)[t(23)=2.33$, $p<.05]$. The false alarm rates of pleasant (.33) and neutral $(.32)$ words did not differ significantly $[t(23)=0.14$, $p=.89]$.

The main result of Experiment 3 was that emotional word lists were recognized better than neutral word lists. Before discussing our results further, we will report an 
Table 2

Mean Proportions (With Standard Deviations) of

Hit and False Alarm Rates As a Function of Pleasantness in Experiments 3 and 4 (Serial Recognition)

\begin{tabular}{|c|c|c|c|c|c|c|c|c|}
\hline \multirow[b]{3}{*}{ Responses } & \multicolumn{4}{|c|}{$\begin{array}{c}\text { Experiment } 3 \\
\text { (Limited Word Set) }\end{array}$} & \multicolumn{4}{|c|}{$\begin{array}{c}\text { Experiment } 4 \\
\text { (Open Word Set) }\end{array}$} \\
\hline & \multicolumn{2}{|c|}{$\begin{array}{l}\text { Pleasant } \\
\text { Words }\end{array}$} & \multicolumn{2}{|c|}{$\begin{array}{c}\text { Neutral } \\
\text { Words }\end{array}$} & \multicolumn{2}{|c|}{$\begin{array}{l}\text { Pleasant } \\
\text { Words }\end{array}$} & \multicolumn{2}{|c|}{$\begin{array}{l}\text { Neutral } \\
\text { Words }\end{array}$} \\
\hline & $M$ & $\overline{S D}$ & $M$ & $S D$ & $M$ & $\overline{S D}$ & $M$ & $S D$ \\
\hline Hits & .75 & .11 & .66 & .17 & .69 & .11 & .62 & .14 \\
\hline False alarms & .33 & .19 & .32 & .24 & .31 & .24 & .40 & .23 \\
\hline
\end{tabular}

attempt to replicate this effect with the same unlimited set of items as that in Experiment 2.

\section{EXPERIMENT 4}

\section{Method}

Participants. Twenty-four 2nd-year psychology students at Paul Valéry University (mean age, 20 years) volunteered to participate in the experiment. All were native French speakers.

Materials and Design. The materials were identical to those employed in Experiment 2 in terms of experimental words (56 pleasant and 56 neutral words) and memory lists (eight 7-word lists from the pleasant set and eight 7 -word lists from the neutral set). The 8 lists for each word condition were used to construct 4 identical and 4 different lists following exactly the same design as that in Experiment 3. Each participant saw the 16 identical and different lists, which were presented in a random order, with the constraint of having, at most, 3 lists of the same type in a row (i.e., identical or different).

Procedure. The procedure was the same as that in Experiment 3.

\section{Results}

As in Experiment 3, accuracy was calculated for each condition (pleasant vs. neutral words). The mean $d^{\prime}$ for pleasant words was $2.10(S D=1.15)$, whereas it was 1.29 $(S D=1.49)$ for neutral words. This difference was significant $[t(23)=2.24, p<.05]$. Recognition accuracy was greater for pleasant than for neutral lists. Table 2 shows the hit and false alarm rates in each condition. Hit rates were higher for pleasant words (.69) than for neutral ones (.62) $[t(23)=2.33, p<.05]$. The false alarm rates of pleasant (.31) and neutral (.40) words did not differ significantly $[t(23)=1.52, p=.14]$.

\section{Discussion}

The results of Experiment 4 confirm the findings of Experiment 3 in that they demonstrated a pleasantness effect on an immediate serial recognition task. So, there is no doubt that the pleasantness effect observed in immediate serial recall (Experiments 1 and 2) can still occur in serial recognition (Experiments 3 and 4). This finding seems to go against a number of results reported in the literature, including those obtained by Walker and Hulme (1999) when the semantic variable manipulated was concreteness. In their study, Walker and Hulme found equivalent serial recognition performance for concrete and abstract words (Experiment 4) despite a clear serial recall advantage for concrete words (Experiment 1). This apparent contradiction may be due to a problem of task sensitiv- ity. Walker and Hulme used a matching span procedure in which the list length was gradually increased until the participants no longer responded accurately. This type of span procedure may turn out to be less sensitive to semantic factors than is a procedure involving a fixed number of items per list. The problem may also stem from the magnitude of the effect of the semantic variable manipulated. One could contend that the pleasantness variable influences verbal STM to a greater extent than does concreteness. However, if this is true, it should also be reflected in performance on immediate serial recall, which does not seem to be the case $(8.6 \%$ recall advantage in Walker \& Hulme, 1999, vs. $9 \%$ and $8 \%$ here in Experiments 1 and 2, respectively). Let us mention one final potential explanation. In the present study, the pleasantness factor had an impact on memory for both item identity and item order (Experiments 1 and 2), whereas in previous studies, the impact of lexical/semantic factors has generally been confined to memory for item identity (e.g., Gathercole et al., 2001; Hulme et al., 1997; Walker \& Hulme, 1999). One can thus argue in the present case that a recognition task consisting of detecting changes in the order of the list items is more sensitive to the manipulated semantic factor. Given that the order of pleasant words is retained better than the order of neutral words, one should indeed find better detection of item transposition when pleasant words are being recognized.

The finding that pleasantness effects occurred in an immediate serial recognition task seems inconsistent with the claim made by some proponents of the redintegration account, that serial recognition does not require redintegration (e.g., Gathercole et al., 2001). This result is compatible, however, with the position defended by other proponents of the redintegration model (Neath, 1997), according to which recognition at testing time involves the activation of a mental representation (the items in the first order) that will be compared with external information (i.e., the items in the second order). If the mental representation happens to be degraded, the redintegration process will take effect, with its efficiency depending on the quality of the long-term representations. Finally, the fact that pleasantness effects still occurred here in recognition is also compatible with psycholinguistic models of STM, which assume semantic intervention starting at encoding time and continuing throughout the task.

\section{CONCLUSION}

By manipulating word pleasantness, the present study was able to offer some new supporting arguments for a semantic contribution to verbal STM. Word pleasantness was found to affect immediate serial recall and had the particularity of also affecting performance on an immediate serial recognition task. This last finding allows us to rule out the view of recognition tasks whereby they are pure order memory tasks that bypass the redintegration process. It remains interpretable, nonetheless, in terms of the nonlinguistic redintegration model, provided we accept Neath's (1997) claim that meeting rec- 
ognition task demands requires comparing an internal representation of previously presented information with external information. Finally, our results as a whole are fully compatible with psycholinguistic models of STM, which predict parallel effects of semantic factors in serial recall and recognition. Even though both classes of models turned out to be capable of accounting for the main results of the present study, the mechanisms proposed to explain the observed phenomena are quite different. Whereas nonlinguistic models of STM confine the implication of semantic knowledge to the retrieval phase, psycholinguistic models posit the intervention of semantic knowledge throughout task execution - that is, during encoding, retention, and testing. The explanation we propose for why memory for order is better when the to-be-remembered words are pleasant (i.e., better source memory) suggests that the impact of word pleasantness takes effect already at item-encoding time. In this sense, it seems more compatible with psycholinguistic approaches to verbal STM.

\section{AUTHOR NOTE}

We thank Jean Saint-Aubin and two anonymous referees for their helpful comments on earlier versions of the manuscript. Correspondence concerning this article should be addressed to C. Monnier, Département de Psychologie, Université Paul Valéry, Route de Mende, 34199 Montpellier Cedex 5, France (e-mail: catherine.monnier@univ-montp3.fr).

\section{REFERENCES}

Allen, R., \& Hulme, C. (2006). Speech and language processing mechanisms in verbal serial recall. Journal of Memory \& Language, 55, 64-88.

Baddeley, A., Gathercole, S., \& Papagno, C. (1998). The phonological loop as a language learning device. Psychological Review, 105, $158-173$.

Bock, M. (1986). The influence of emotional meaning on the recall of words processed for form or self-reference. Psychological Research, 48, 107-112.

Bonin, P., Méot, A., Aubert, L., Malardier, N., Niedenthal, P., \& CAPElle-ToczeK, M.-C. (2003). Normes de concrétude, de valeur d'imagerie, de fréquence subjective et de valence émotionnelle pour 866 mots. L'Année Psychologique, 104, 655-694.

Bourassa, D. C., \& Besner, D. (1994). Beyond the articulatory loop: A semantic contribution to serial order recall of subspan lists. Psychonomic Bulletin \& Review, 1, 122-125.

Bower, G. H. (1981). Mood and memory. American Psychologist, 36, 129-148.

Capaldi, E. J., \& Neath, I. (1995). Remembering and forgetting as context discrimination. Learning \& Memory, 2, 107-132.

CaZA, N., \& Belleville, S. (1999). Semantic contribution to immediate serial recall using an unlimited set of items: Evidence for a multilevel capacity view of short-term memory. International Journal of Psychology, 34, 334-338.

Content, A., Mousty, P., \& Radeau, M. (1990). Brulex, une base de données lexicales informatisée pour le français écrit et parlé. L'Année Psychologique, 90, 551-566.

Doerksen, S., \& Shimamura, A. P. (2001). Source memory enhancement for emotional words. Emotion, 1, 5-11.

FERRÉ, P. (2003). Effects of level of processing on memory for affectively valenced words. Cognition \& Emotion, 17, 859-880.

Gathercole, S. E., Pickering, S. J., Hall, M., \& Peaker, S. M. (2001). Dissociable lexical and phonological influences on serial recognition and serial recall. Quarterly Journal of Experimental Psychology, 54A, 1-30.

HadLey, B. C., \& MacKay, D. G. (2006). Does emotion help or hinder immediate memory? Arousal versus priority-binding mechanisms. Journal of Experimental Psychology: Learning, Memory, \& Cognition, 32, 79-88.

Hulme, C., Maughan, S., \& Brown, G. D. A. (1991). Memory for familiar and unfamiliar words: Evidence for a long-term memory contribution to short-term memory span. Journal of Memory \& Language, 30, 685-701.

Hulme, C., Roodenrys, S., Schweickert, R., Brown, G. D. A., MarTIN, S., \& StUART, G. (1997). Word-frequency effects on short-term memory tasks: Evidence for a redintegration process in immediate serial recall. Journal of Experimental Psychology: Learning, Memory, \& Cognition, 23, 1217-1232.

JefFeries, E., Frankish, C. R., \& Lambon RalPh, M. A. (2006a). Lexical and semantic binding in verbal short-term memory. Journal of Memory \& Language, 54, 81-98.

JefFeries, E., Frankish, C. R., \& Lambon RalPh, M. A. (2006b). Lexical and semantic influences on item and order memory in immediate serial recognition: Evidence from a novel task. Quarterly Journal of Experimental Psychology, 59, 949-964.

Johnson, M. K., Hashtroudi, S., \& Lindsay, D. S. (1993). Source monitoring. Psychological Bulletin, 114, 3-28.

Knott, R., Patterson, K., \& Hodges, J. R. (2000). The role of speech production in auditory-verbal short-term memory: Evidence from progressive fluent aphasia. Neuropsychologia, 14, 125-142.

Martin, N., \& Gupta, P. (2004). Exploring the relationship between word processing and verbal short-term memory: Evidence from associations and dissociations. Cognitive Neuropsychology, 21, 213-228.

MARTIN, N., \& SAFFrAn, E. M. (1997). Language and auditory-verbal short-term memory impairments: Evidence for common underlying processes. Cognitive Neuropsychology, 14, 641-682.

Murdock, B. B., JR. (1976). Item and order information in short-term serial memory. Journal of Experimental Psychology: General, 105, 191-216.

NaIRne, J. S. (1990). A feature model of immediate memory. Memory \& Cognition, 18, 251-269.

NAIRNE, J. S. (2002). Remembering over the short-term: The case against the standard model. Annual Review of Psychology, 53, 53-81.

NeAth, I. (1997). Modality, concreteness, and set-size effects in a free reconstruction of order task. Memory \& Cognition, 25, 256-263.

New, B., Pallier, C., Ferrand, L., \& Matos, R. (2001). Une base de données lexicales du français contemporain sur Internet: LEXIQUE. L'Année Psychologique, 101, 447-462.

Niedenthal, P. M., Barsalou, L. W., Winkielman, P., KrauthGruber, S., \& Ric, F. (2005). Embodiment in attitudes, social perception, and emotion. Personality \& Social Psychology Review, 9, 184-211.

OCHSNER, K. N. (2000). Are affective events richly recollected or simply familiar? The experience and process of recognizing feelings past. Journal of Experimental Psychology: General, 129, 242-261.

OsGood, C. E., \& SuCI, G. J. (1955). Factor analysis of meaning. Journal of Experimental Psychology, 50, 325-338.

Osgood, C. E., Suci, G. J., \& Tannenbaum, P. H. (1957). The measurement of meaning. Urbana: University of Illinois Press.

Patterson, K., Graham, N., \& Hodges, J. R. (1994). The impact of semantic memory loss on phonological representations. Journal of Cognitive Neuroscience, 6, 57-69.

Poirier, M., \& SAINT-Aubin, J. (1995). Memory for related and unrelated words: Further evidence on the influence of semantic factors in immediate serial recall. Quarterly Journal of Experimental Psychology, 48A, 384-404.

PoIrier, M., \& SAINT-Aubin, J. (1996). Immediate serial recall, word frequency, item identity and item position. Canadian Journal of Experimental Psychology, 50, 408-412.

Rogers, T. B., Kuiper, N. A., \& KirKner, W. S. (1977). Self-reference and the encoding of personal information. Journal of Personality \& Social Psychology, 35, 677-688.

Roodenrys, S., Hulme, C., Lethbridge, A., Hinton, M., \& Nimmo, L. M. (2002). Word-frequency and phonological-neighborhood effects on verbal short-term memory. Journal of Experimental Psychology: Learning, Memory, \& Cognition, 28, 1019-1034.

Saint-Aubin, J., Ouellette, D., \& Poirier, M. (2005). Semantic 
similarity and immediate serial recall: Is there an effect on all trials? Psychonomic Bulletin \& Review, 12, 171-177.

SAINT-Aubin, J., \& PoIrIER, M. (1999). Semantic similarity and immediate serial recall: Is there a detrimental effect on order information? Quarterly Journal of Experimental Psychology, 52A, 367-394.

SAINT-Aubin, J., \& PoIRIER, M. (2000). Immediate serial recall of words and nonwords: Tests of the retrieval-based hypothesis. Psychonomic Bulletin \& Review, 7, 332-340.

SCHWEICKERT, R. (1993). A multinomial processing tree model for degradation and redintegration in immediate recall. Memory \& Cognition, 21, 168-175.

SysSAU, A., \& FonT, N. (2005). Evaluations des caractéristiques émotionnelles d'un corpus de 604 mots. Bulletin de Psychologie, 58, 361-367.

Walker, I., \& Hulme, C. (1999). Concrete words are easier to recall than abstract words: Evidence for a semantic contribution to shortterm serial recall. Journal of Experimental Psychology: Learning, Memory, \& Cognition, 25, 1256-1271.

\section{NOTES}

1. An immediate serial recognition task involves the presentation of a list of verbal items, followed immediately by the presentation of a second list containing the same items in either the same or a different order. The participant has to judge whether or not the two lists are different.

2. It should be noted, however, that a number of contradictory findings on this point have been reported in the literature. Saint-Aubin et al. (2005) found an effect of semantic similarity on order errors in favor of unrelated words. Allen and Hulme (2006) observed a higher proportion of order errors for abstract words than for concrete words.

(Manuscript received May 10, 2005;

revision accepted for publication May 29, 2007.) 